\title{
Growth Rate and Morphology of a Single Calcium Carbonate Crystal on Polysulfone Film Measured with Time Lapse Raman Micro Spectroscopy
}

\section{Barbara Liszka $\mathbf{M}^{1,2 *}$, Aufried Lenferink TM${ }^{1}$ and Cees Otto ${ }^{1 *}$}

${ }^{1}$ Department of Medical Cell Biophysics, MIRA Institute, University of Twente, Enschede, The Netherlands

${ }^{2}$ Wetsus, European Centre of Excellence for Sustainable Water Technology, Leeuwarden, The Netherlands

\begin{abstract}
The growth of single, self- nucleated calcium carbonate crystals on a polysulfone (PSU) film was investigated with high resolution, time lapse Raman imaging. The Raman images were acquired on the interface of the polymer with the crystal. The growth of crystals could thus be followed in time. PSU is a polymer that is used as a membrane material in water cleaning technology. The intensity of the Raman band at the position of $1086 \mathrm{~cm}^{-1}$, which is due to the symmetric stretching of the $\mathrm{C}-\mathrm{O}$ bonds in the carbonate group of calcite was used to translate the number of $\mathrm{CO}^{2-}$ ions in a crystal to the growth in time. The growth rate of single crystals of calcium carbonate on a surface was obtained from successive Raman images. We are presenting for the first time time-lapse Raman images of single crystal growth as a direct method to determine a crystal growth rate on an industrially relevant membrane material, like polysulfone.
\end{abstract}

Keywords: Crystal growth rate; Calcium carbonate; Raman imaging; Polymer surface; Time lapse images

Abbreviations: PSU: Polysulfone; SS1: Solution made by mixing of $4 \mathrm{mM} \mathrm{NaHCO}_{3}$ and $8 \mathrm{mM}$ of $\mathrm{CaCl}_{2}$; SS2: Solution made by mixing of $10 \mathrm{mM} \mathrm{NaHCO}_{3}$ and $10 \mathrm{mM}$ of Calcium chloride $\left(\mathrm{CaCl}_{2}\right)$; ROI: Region of Interest.

\section{Introduction}

The phenomenon of calcium carbonate crystal growth from aqueous solutions on surfaces widely occurs in systems where carbonate and bicarbonate ions are present, such as in domestic systems, waste and drinkable water treatment systems or industrial apparatus where water is used. Crystal growth leads to the formation of mineral scale which reduces the performance of membrane materials in equipment. The scale development is affected by factors such as: $\mathrm{pH}$, super-saturation index, temperature, water composition etc. stages:

The process of scaling and crystal growth includes the following

1) The induction period involve nucleation and crystal growth.

2) The mineralizing crystals and others particles transportation from the bulk and its adhesion to the surface,

3) Ageing of crystals at a surface, for instance due to recrystallization and dehydration.

Other components present in a mineralizing solution could increase or decrease the crystal growth rate by adhesion to crystal surfaces.

The abovementioned physico-chemical factors play an important role in crystal growth on a surface and hence in the performance over time of membrane materials. An understanding of the kinetics governing formation and growth of calcium carbonate crystals on surface is important to gain the ability to predict, control and direct or stop this process. Many studies have been performed of calcium carbonate crystal growth on a macroscopic scale using indirect methods that monitor changes of solution chemistry [1]. These studies have revealed a dependence of growth kinetics upon parameters such as $\mathrm{pH}$, supersaturation ratio, ionic strength or temperature [2-4]. Atomic Force Microscopy (AFM) has been extensively used to study mechanisms and growth rates of single crystals from solution [5-7], including calcite crystals [1,8-14]. The high resolution of AFM can visualize monomolecular steps on atomically flat crystal surfaces. It has been also observed that the AFM tip can influence the growth rate under supersaturated conditions [9]. Vertical scanning interferometry is an alternative approach to study growth rates and morphology of single barite crystals [5]. In these approaches the mineralization was studied after seeding. Therefore a measured growth rate is dependent on e.g., seed preparation method. In another study, cryo-electron tomography was used to investigate self-nucleated, template controlled growth of $\mathrm{CaCO}_{3}$ crystals from the solution-phase [15]. Early crystallization events of a few nanometer were observed.

Raman micro-spectroscopy is a well-established method to study crystal morphology as it provides information about the chemical composition and crystal polymorphism [16-20]. The method enables investigations under ambient conditions in an aqueous environment. Raman micro-spectroscopy is a non-invasive, contact-free method that does not influence crystal formation. Furthermore, the method is quantitative as the Raman scattering intensity of a typical group vibration is directly related to the total number of that chemical group.

This paper presents time lapse Raman spectroscopic imaging for in situ study of single calcium carbonate crystals growing on a polysulfone film under diffusion-limited conditions in a stagnant solution. In time lapse Raman imaging a time-sequence of Raman images is made

*Corresponding authors: Barbara Maria Liszka, Department of Medical Cell Biophysics, MIRA Institute, University of Twente, Enschede, The Netherlands E-mail: b.liszka@utwente.nl

Cees Otto, Department of Medical Cell Biophysics, MIRA Institute, University of Twente, Enschede, The Netherlands, E-mail: c.otto@utwente.nl

Received April 19, 2016; Accepted May 17, 2016; Published May 23, 2016

Citation: Liszka BM, Lenferink ATM, Otto C (2016) Growth Rate and Morphology of a Single Calcium Carbonate Crystal on Polysulfone Film Measured with Time Lapse Raman Micro Spectroscopy. J Anal Bioanal Tech 7: 321. doi:10.4172/2155 9872.1000321

Copyright: @ 2016 Liszka BM, et al. This is an open-access article distributed under the terms of the Creative Commons Attribution License, which permits unrestricted use, distribution, and reproduction in any medium, provided the original author and source are credited. 
of a region of interest. All the individual images can be analyzed simultaneously to provide physico-chemical data of the growing crystal. It will be shown below that the mass growth rate of individual calcite crystals can be obtained directly from time lapse Raman images.

\section{Materials and Methods}

\section{Materials}

Sodium bicarbonate $\left(\mathrm{NaHCO}_{3}\right)$, calcium chloride $\left(\mathrm{CaCl}_{2}\right)$, potassium chloride $(\mathrm{KCl})$, sodium hydroxide $(\mathrm{NaOH})$ was of analytical grade and obtained from Sigma Aldrich, Germany. Pellets of polysulfone (PSU) with 35,000 Mw was purchased from Sigma Aldrich, Germany. Cyclopentanone was used as a solvent for polysulfone thin film production. Analytical grade cyclopentanone was purchased from Fluka Analytical. Raman grade calcium fluoride windows with a thickness of $200 \mu \mathrm{m}$ and a diameter of $1 \mathrm{~cm}$ were obtained from Crystran Ltd.

\section{Methods}

Liquid cell: A liquid cell was custom made from glass (DURAN ${ }^{\star}$ borosilicate) with a volume of $32 \mathrm{ml}$. At the top of the cell a window with a diameter of $0.8 \mathrm{~mm}$ was made by removing the glass by cutting. The window was sealed with $200 \mu \mathrm{m}$ calcium fluoride disc $\left(\mathrm{CaF}_{2}\right)$. The disc was covered with a $4.5 \pm 1.5 \mathrm{~mm}$ thin polysulfone film. The polymercovered surface was mounted towards the interior of the liquid cell. The orientation of the active polysulfone surface above the mineralization solution avoided sedimentation on the surface of crystals that may have grown in solution. High resolution Raman imaging could be performed on the interface polymer- mineralization solution with a high numerical aperture $(\mathrm{NA}=0.95)$ objective with a working distance of $300 \mu \mathrm{m}$. $\mathrm{CaF}_{2}$ was selected as a substrate because this material gives minimal optical contributions to the Raman scattering. The cell was placed on a microscope stage with the measurement window towards the objective. Measurements were performed in a closed liquid cell to prevent exchange of carbon dioxide from the chamber with the atmosphere. A schematic figure of the fluidic cell is presented in Figure
1A. The Raman signal was acquired by stepping the laser in $x-$ and $y$ directions over the region of interest. The Raman spectral information comes from a laser focal volume (c), with an ellipsoidal shape with dimensions of $1500 \mathrm{~nm}$ (a) by $330 \mathrm{~nm}$ in diameter (b), shown in Figure $1 \mathrm{~B}$ together with a schematic representation of imaging.

The liquid cell was cleaned before use with $1 \mathrm{M} \mathrm{H}_{2} \mathrm{SO}_{4}$ and rinsed thoroughly with milliQ water. The polysulfone film was prepared by dissolving polymers pellets in cyclopentanone up to a $0.4 \% \mathrm{wt}$ concentration. The entire calcium fluoride window was wetted with a polymer solution and the substrate was accelerated to a spin speed of $4000 \mathrm{rpm}$. The total spinning time was $6 \mathrm{~s}$. The thickness of the polysulfone film was determined to $4.5 \pm 1.5 \mathrm{~mm}$.

Supersaturated solutions: Two types of supersaturated solution were prepared, which will be distinguished as SS1 and SS2. In order to prepare solution SS1 two solutions of $250 \mathrm{~mL}$ of $\mathrm{NaHCO}_{3}(4.0 \mathrm{mM})$ and $\mathrm{CaCl}_{2}(8.0 \mathrm{mM})$ were prepared. The ionic strength was adjusted to 0.10 by the addition of $3.2 \mathrm{~g} \mathrm{KCl}$ to the solution of $\mathrm{NaHCO}_{3}$. The $\mathrm{pH}$ was adjusted to a value of 8.89 by the addition of $30 \mu \mathrm{L}$ of aqueous $\mathrm{NaOH}(3.0 \mathrm{M})$ to the solution of $\mathrm{CaCl}_{2}$. The final SS1 was prepared by mixing aqueous solutions of $\mathrm{NaHCO}_{3}$ and $\mathrm{CaCl}_{2}$ in a ratio of $1: 1$ to obtain the desired volume.

SS2 was prepared by mixing $250 \mathrm{~mL}$ of a solution of $\mathrm{NaHCO}_{3}(10.0$ $\mathrm{mM})$ and $250 \mathrm{~mL}$ of a solution of $\mathrm{CaCl}_{2}(10.0 \mathrm{mM})$. All solutions were prepared with Milli-Q water.

The driving force for crystals formation is the super-saturation ratio, which is defined in following equation:

$$
\frac{\Delta \mu}{R T}=\vartheta \ln (S)
$$

Where $R\left[\mathrm{~J} \mathrm{~mol}^{-1} \mathrm{~K}^{-1}\right]$ is the gas constant, $T[K]$ is the absolute temperature, $\Delta \mu\left(\mathrm{J} \mathrm{mol}^{-1}\right)$ is the change in chemical potential of ions in the crystal $\left(\mu_{i c}\right)$ and the chemical potential of ions in the liquid phase ( $\mu i L) . \vartheta$ is the number of ions in the formula units (for $\mathrm{CaCO}_{3} v=2$ ), $S$ is super-saturation ratio.
A
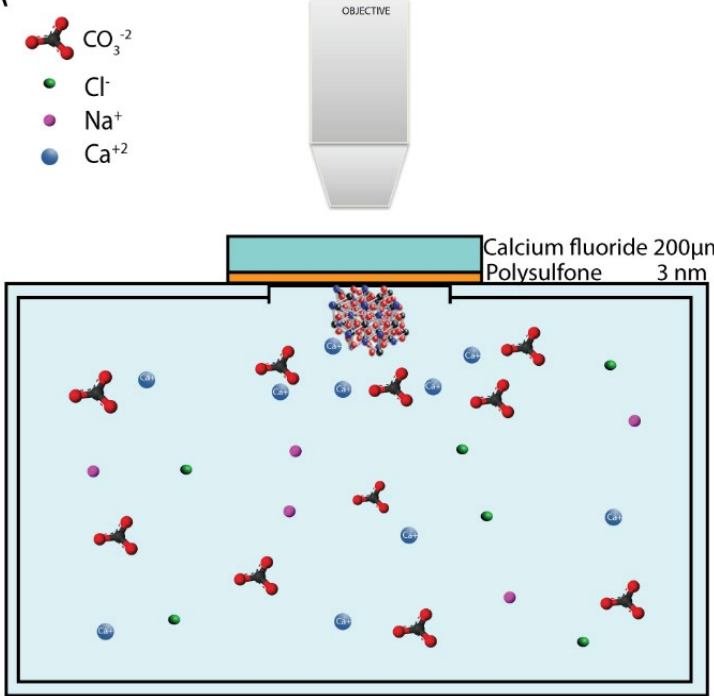

B

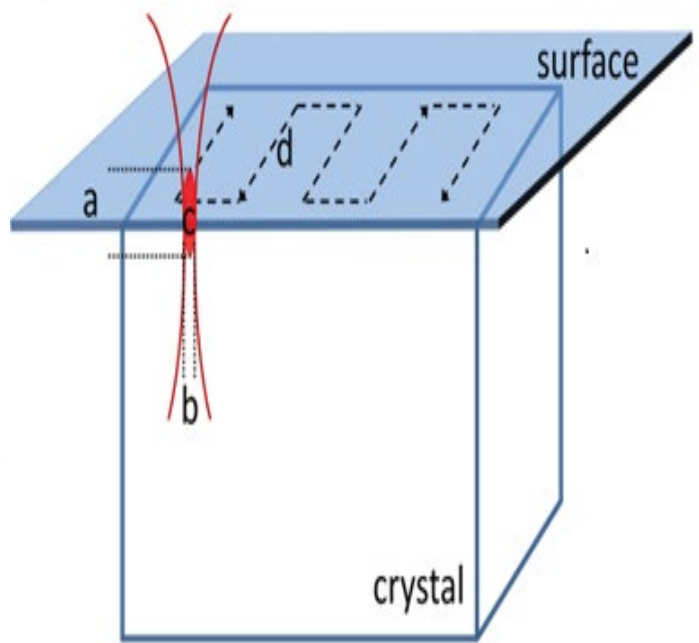

Figure 1: A) Schematic representation of the liquid cell. B) Schematic representation of the scanning procedure in Raman imaging: "c" is the laser focal volume with dimensions a: $1500 \mathrm{~nm}$ and b: $330 \mathrm{~nm}$. The laser is focused on the surface and image is acquired by stepping the laser along the lines e. Vertical and horizontal dimensions in this schematic representation are not to scale. 
For ionic solutions, such as $\mathrm{CaCO}_{3}$, the super-saturation can best be expressed in terms of ion activities [21].

$$
s=\left(\frac{I A P}{K_{s p}}\right)^{1 / \vartheta}
$$

Where IAP is the ion activity product, $K_{s p}$ is the thermodynamic solubility product, which is $3.36 \times 10^{-9}$ for calcium carbonate in the calcite structure [22]

The super-saturation ratio and the chemical speciation of the solutions in this study were calculated in the program Visual MinteQ 3.1 from the total concentration of ions in solution $\left(\mathrm{Cl}^{-}, \mathrm{Ca}^{2+}, \mathrm{Na}^{+}, \mathrm{H}^{+}\right.$, $\mathrm{CO}_{3}^{2-}, \mathrm{K}^{+}$) and the activity coefficients as computed by the program [23-25].

Confocal Raman micro spectrometer and data analysis: All Raman measurement were conducted with a home-built Raman spectrometer [26]. The excitation source was a $\mathrm{Kr}$-ion laser (Coherent, Innova 90-K. Santa Clara, CA) with an emission wavelength of $647.09 \mathrm{~nm}$. Raman spectra were acquired using an objective with $40 \mathrm{X}$ magnification and a NA of 0.95 . A pinhole with a diameter of $15 \mu \mathrm{m}$ functioned as the entrance aperture to the spectrograph. The spectrograph dispersed the light in the range from $645-847 \mathrm{~nm}$. The Raman signal was detected by a back illuminated CCD camera with $1600 \times 200$ pixels (Newton DU970N-BV; Andor Technology). The combined spectrograph and CCD camera recorded Raman shifts between $-50 \mathrm{~cm}^{-1}$ and $3650 \mathrm{~cm}^{-1}$.

The series of images were acquired under following conditions for SS1 laser power $75 \mathrm{~mW}$, an acquisition time $0.1 \mathrm{~s} /$ per pixel, Raman maps $32 \times 32$ spectra, and for SS2 laser power $80 \mathrm{~mW}$, an acquisition time $0.034 \mathrm{~s} /$ per pixel, Raman maps $32 \times 32$ spectra. The position of a crystal was located on the polysulfone surface by bright field optical microscopy. Crystals with a diameter larger than $100 \mathrm{~nm}$ could be discerned by bright field microscopy. The Raman excitation laser beam was focused on the polymer surface. The Raman images were acquired with the crystal in the center of the region of interest (ROI). The position of the ROI was adjusted in between images during time lapse measurement to follow the direction of crystal growth. The size of the square ROI was adjusted to the size of the crystal. The images were taken one after another with user defined time delay between images.

The measured Raman spectra were corrected for:

1) Cosmic ray events,

2) wavelength-dependence of the sensitivity of the complete Raman spectrometer,

3) CCD camera-etaloning,

4) Absolute amplitude correction by a calibrated tungsten halogen lamp and

5) Conversion from pixels to wavenumbers by the combined output from a mercury-argon lamp and the recorded Raman spectrum of toluene.

After this procedure fully corrected Raman spectra were stored and used for further analysis.

The corrected Raman spectra were subjected to singular value decomposition (SVD) to improve the signal to noise ratio [27]. The Raman scattering intensity in each pixel of the time lapse images was determined with a custom written Labview program. The intensity was calculated for the carbonate vibrational mode at $1086 \mathrm{~cm}^{-1}$ after subtraction of a local linear baseline between selected anchor points left and right of the band of interest.

\section{Results and Discussion}

The onset of crystal growth was monitored by bright field microscopy and upon the observation of crystal growth event the region of interest (ROI) of the polysulfone polymer surface was monitored by time lapse Raman imaging with the crystal in the center of the ROI. The intensity of the carbonate ion symmetric stretch vibration at a position of $1086 \mathrm{~cm}^{-1}$ was used to construct images. Each resulting Raman image shows the morphology of the crystal and the time sequence of the images shows crystal growth from a supersaturated solution (Figure $2 \mathrm{~A}$ ). The region of interest in the first four images was $4.5 \mu \mathrm{m} \times 4.5$ $\mu \mathrm{m}$. The step size (x,y) of the laser scanner was $146 \mathrm{~nm}$. This step size is in accordance with the Nyquist sampling frequency for optimal information retrieval. The $5^{\text {th }}$ to $15^{\text {th }}$ images were acquired with a step size of $397 \mathrm{~nm}$ to maintain a clear border between the growing crystal and the edge of the region of interest. An example of an average Raman spectrum of a crystal is presented in Figure 2B. The characteristic Raman frequencies of carbonate ion in a calcite crystal lattice occur at $1086 \mathrm{~cm}^{-1}$ : C-O symmetric stretching, $711 \mathrm{~cm}^{-1}$ : C-O antisymmetric stretching, $1436 \mathrm{~cm}^{-1}, 1750 \mathrm{~cm}^{-1}: \mathrm{C}=\mathrm{O}$ stretching and lattice related modes in positions at $156 \mathrm{~cm}^{-1}$ and at $282 \mathrm{~cm}^{-1}$ [17,20-28]. The Raman spectra therefore, show that the crystal on a PSU film formed in a calcite polymorphism. The presence of calcite polymorph was observed in all the Raman images of the time lapse series. The earliest image was obtained 25 minutes after mixing. No Raman bands of other calcium carbonate polymorphs, like vaterite, aragonite or amorphous calcium carbonate, could be discerned. Calcite is thermodynamically the most stable polymorph of calcium carbonate and no changes were observed in crystal polymorphism during growth. The Raman spectrum of the $4.5 \pm 1.5 \mathrm{~nm}$ polysulfone polymer layer that acted as the active material for crystal growth is shown in Figure 2C. The spectrum contains characteristics PSU bands in position $1073,1108,1148 \mathrm{~cm}^{-1}$. The band in the position $1086 \mathrm{~cm}^{-1}$, characteristic for carbonate, is still visible in the spectrum of the background as weak contributions from crystal edges contribute to the background signal.

The anisotropic growth of the crystal after the first 43 minutes can be observed in the images presented in Figure 2A. After the image taken at 43 minutes, the crystal starts to grow irregularly due to rapid anisotropic growth. The positions at the crystal surface where irregular growth occurs are marked in the images by arrows. The irregularity in the crystal shape disappears during its growth and in the last image, acquired after $24 \mathrm{~h}$, the crystal achieved a regular shape very familiar for calcite crystals.

\section{Single crystal growth rate from time lapse Raman images}

The intensity of Raman bands is proportional to the number of molecules in the measurement volume, which is the volume effectively sampled by the laser focal volume. The calcite single unit cell has a rhombohedral shape with dimensions $\mathrm{a}=\mathrm{b}=4.9896 \AA \mathrm{A}, \mathrm{c}=17.061 \AA$, and the number of calcite groups in the unit cell $Z=6$ [29]. Based on this data, the number of carbonate molecules in the microscope volume was calculated in case this volume was completely filled with calcite crystal. The Raman scattering cross section, $\sigma_{R}$, of carbonate ion in calcite can be experimentally determined from the number of measured photons, as follows:

$$
\sigma_{R}=\frac{\left(N_{c} h v_{R}\right)}{N_{m} \frac{I_{l}}{A}}
$$



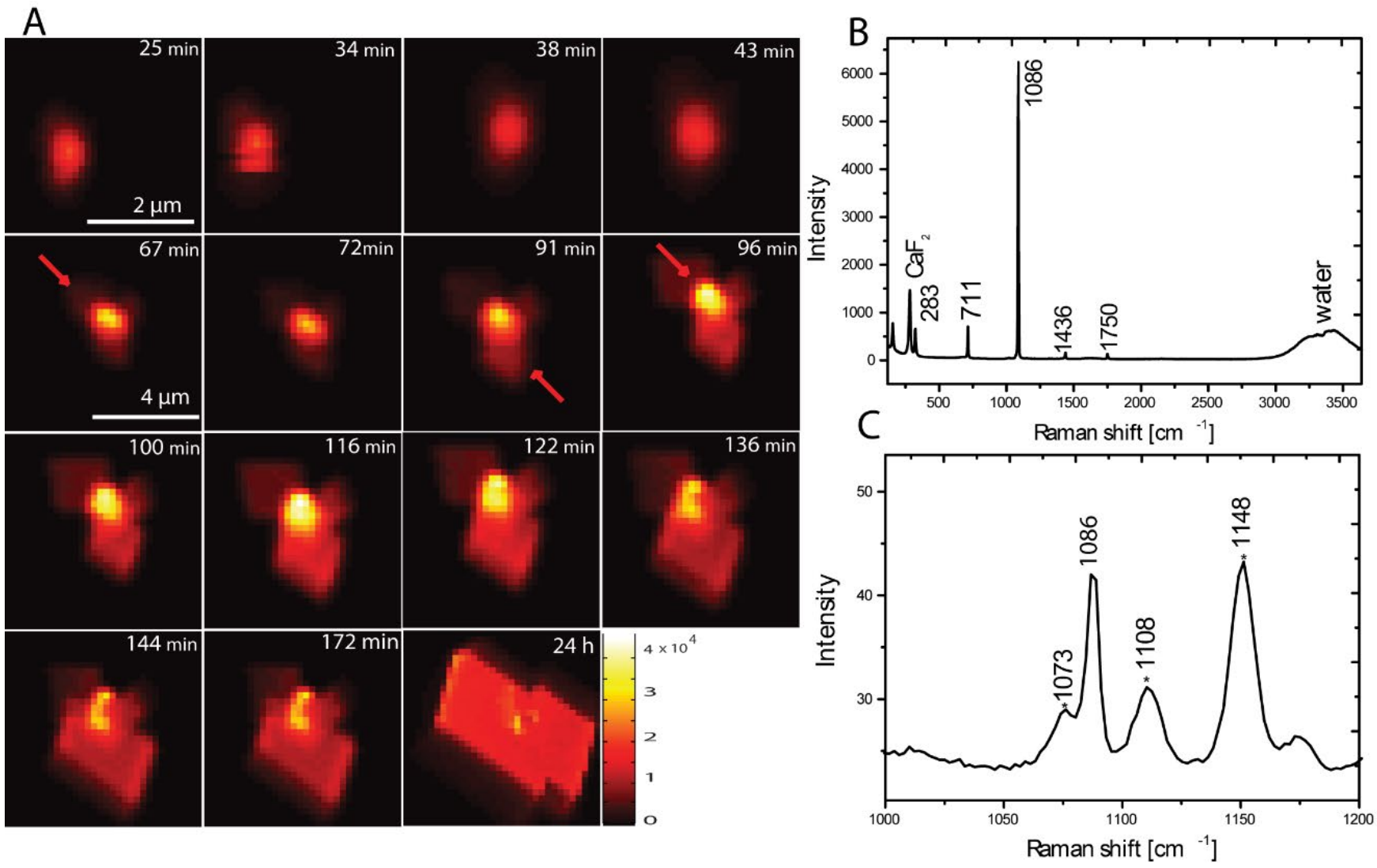

Figure 2: A) Time lapse Raman imaging of $\mathrm{CaCO}$ crystal growth on a polysulfone film. The images are based on the intensity of band at $1086 \mathrm{~cm}^{-1}$. The images were acquired with $75 \mathrm{~mW}$ and an acquisition time of $0.1 \mathrm{~s} /$ pixel. Each image contains 1024 spectra. The arrows show a position of anisotropic growth of the crystal. B) An average Raman spectrum of the calcite crystal, C) An average Raman spectrum of a $4.5 \pm 1.5 \mathrm{~nm}$ polysulfone film.

Where $N_{c}$ is the number of measured counts in the integral intensity of the Raman band of the carbonate ion stretch vibration at $1086 \mathrm{~cm}$ ${ }^{1} ; h=6.63 \times 10^{-34}$ is Planck's constant; $v_{r}$ is the frequency $[1 / \mathrm{s}]$ of the Raman scattered light at $1086 \mathrm{~cm}^{-1}$ upon excitation with the $647.09 \mathrm{~nm}$ laser, $\mathrm{I}_{1}$ is the laser intensity $[\mathrm{W}], \mathrm{A}$ is the area of the laser beam $\left[\mathrm{m}^{2}\right]$ in the focal plane of the microscope objective, $N_{m}$ is the number of $\mathrm{CO}_{3}^{2-}$ ions in the microscope volume.

Equation (2.1) includes the measurement parameters and the set up characteristics to convert the detected number of counts to the emitted and collected photons. With the Raman cross section established, every pixel, with position coordinates $(x, y)$, in the time lapse Raman series of images can be converted to an actual number of carbonate ions $N_{m}$, also when the size of a crystal is smaller than the laser focal volume.

$$
N_{m}(x, y)=\frac{N_{c}(x, y) h v_{R} A}{\sigma_{R} I_{L}}
$$

Figure $3 \mathrm{~A}$ and $3 \mathrm{~B}$ represents individual crystal growth from the super saturated solution SS1. The data were fitted to a quadratic function. Figure $3 \mathrm{C}$ shows crystal growth from a super saturated solution SS2. The starting concentration of solution SS2 was two and a half times higher degree of super saturation than SS1. The higher super saturation leads to a more rapid crystal growth, which was modeled by a sigmodal function, which represents full growth (until ions depletion) during this measurement time measurement time.
The growth rate of a crystal $\mathrm{R}_{\mathrm{G}}$ was calculated from equation 2.3 [21].

$$
R_{G}=\frac{1}{S} \frac{d n}{d t}\left[\mathrm{~mol} \mathrm{~m}^{-2} \mathrm{~s}^{-1}\right]
$$

Where $n$ is the number of moles $\mathrm{CO}_{3}{ }^{2-}$ ions, $S$ is the surface area of one crystal face measured for each time point and $t$ is time.

The surface $S$ of the growing crystal was calculated from the pixels in the Raman images, using the amount of pixels of the measured crystal surface multiplied by the known pixel size. The crystal growth rate was expressed as an average of growth rates calculated per time point $[30,31]$.

The growth rate depends on solution parameters, such as: the supersaturation index (SI), the ionic strength (I), the $\mathrm{pH}$ and the $\left[\mathrm{Ca}^{2+}\right] /\left[\mathrm{CO}_{3}{ }^{2-}\right]$ ratio $[8,32-35]$. Table 1 compares the results from this study with results from the literature [33-35]. Experimental conditions for crystal growth rates vary widely in the literature and importantly influence observed growth rates. The conditions in the literature included in Table 1 most closely approximated the conditions of this study.

The AFM data on crystal growth rate are usually obtained at constant saturation index. In our experiment growth was studied at a starting saturation index of 1.2 , which was not maintained constant during growth. 

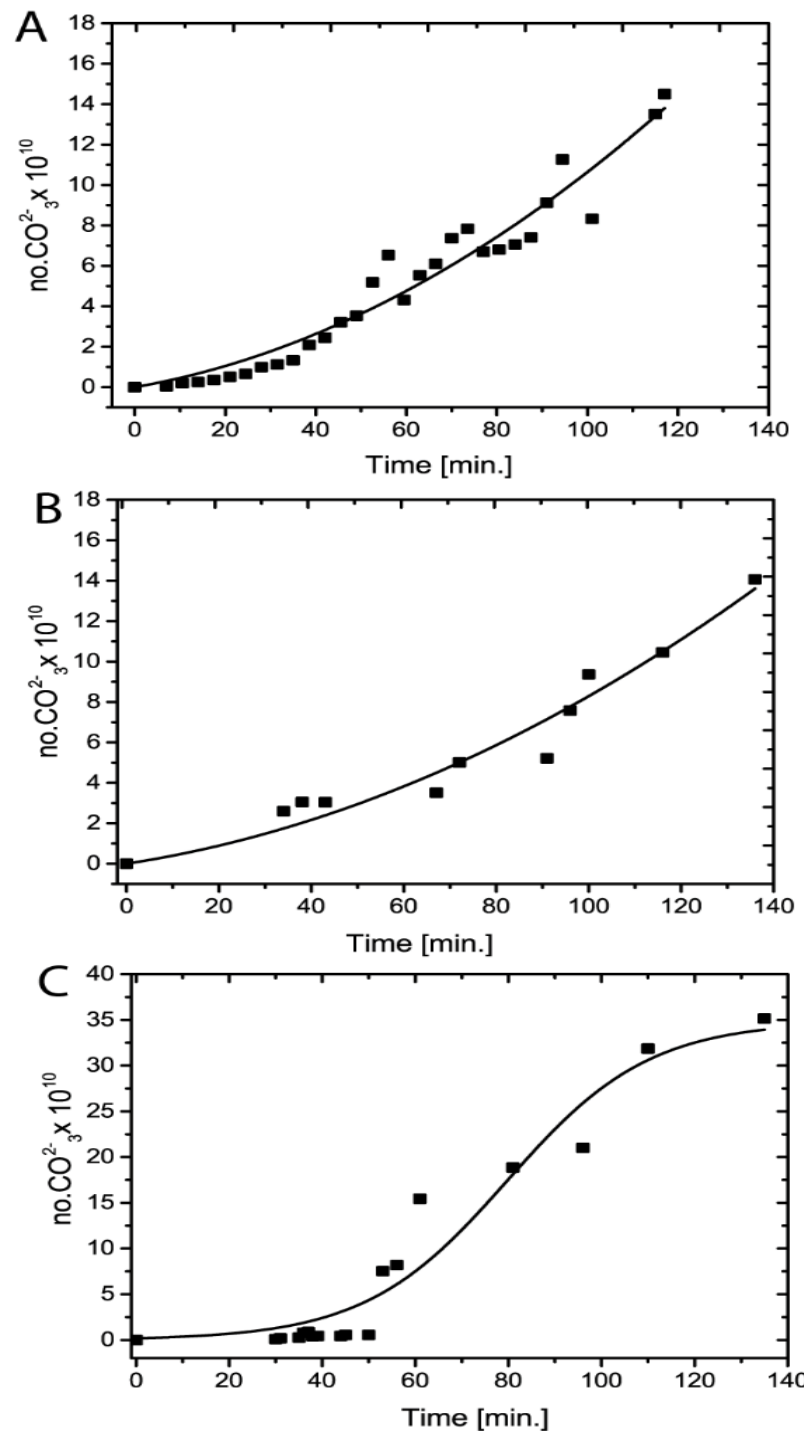

Figure 3: Number of carbonate ions incorporated into a crystal in time. A), B) The curves show crystal growth on PSU film from solution SS1 with a starting concentration of $2 \mathrm{mM}$ of $\mathrm{CO}_{3}{ }^{2}$. The data points were fitted to a quadratic function. C) The curve shows crystal growth from solution SS2 with a starting concentration of $5 \mathrm{mM}$ of $\mathrm{CO}_{3}{ }^{2-}$. The data points were fitted to a sigmoïdal function.

The experimentally determined growth rate (vide supra) is in good correspondence with experimental values obtained in the literature. Especially when considering that in this work, experiments were performed at a higher saturation index of 1.2 and a higher ratio of the calcium ion to carbonate ion concentration. Both aspects tend to increase the growth rate, which was observed. Moreover, the calculated growth rate could be an overestimate, since the focal volume of the laser will also partialkly measure the side surfaces of the growing crystal, which were not included in the calculation.

The growth rate is strongly influenced by the presence of seeds for crystallization. In this work no seeds were used and crystals were spontaneously formed at the active polymer layer. The occurrence of a growth event is rare in the case of unseeded crystallization. Also the location of a growth event is not known beforehand. An increase of

\begin{tabular}{|c|c|c|c|c|}
\hline & $\begin{array}{c}\text { Growth rate }(\mu \mathrm{mol} \\
\left.\mathbf{m}^{-2} \mathbf{s}^{-1}\right) \\
{[\text { References] }}\end{array}$ & {$\left[\mathrm{Ca}^{2+}\right] /\left[\mathrm{CO}_{3}{ }^{2}\right]$} & \multicolumn{2}{|c|}{$\begin{array}{c}\text { Experimental } \\
\text { conditions }\end{array}$} \\
\hline \multirow{2}{*}{ This study } & 2.22 & 2 & $\mathrm{SI}=1.20^{*}$ & $\mathrm{I}=0.1 \mathrm{KCl}$ \\
\cline { 2 - 5 } & 2.64 & 2 & $\mathrm{SI}=1.20^{*}$ & $\mathrm{I}=0.1 \mathrm{KCl}$ \\
\hline \multirow{2}{*}{ Other studies } & $1.25[32,35]$ & 2 & $\mathrm{SI}=0.97 \mathrm{SI}$ & $\mathrm{I}=0.1 \mathrm{KCl}$ \\
\cline { 2 - 5 } & $0.45[31,35]$ & 1 & $\approx 1.00$ & $\mathrm{I}=0.1 \mathrm{NaCl}$ \\
\cline { 2 - 5 } & $1.2 \pm 0.4[35]$ & 2 & $\mathrm{SI}=0.97$ & $\mathrm{I}=0.1 \mathrm{KCl}$ \\
\hline
\end{tabular}

*Starting conditions

Table 1: Crystal growth rates.

the visualization of the number of growth events would be desirable. Therefore an integration of Raman microscopy with a fast method for event recognition, e.g., dark-field microscopy, is required.

\section{Conclusion}

Time lapse Raman imaging was developed as a method to study in situ single, self-nucleated calcite crystals on the surface of an active polysulfone polymer layer. The analysis of the material-specific information in the Raman images enables the extraction of the mass growth rate. The experimentally obtained values for growth rate of calcite from time lapse Raman imaging is in good agreement with values from the literature. Differences in these values can be related to the differences in conditions prior to and during the crystallization process and are in agreement with the expected trend. Further development requires a more efficient search for growth events in spontaneous crystallization.

\section{Author Contributions}

The manuscript was written through contributions of all authors. All authors have given approval to the final version of the manuscript.

\section{Funding Sources}

This work is part of the research program "Spectroscopic analysis of particles in water" which is (partly) financed Fundamenteel Onderzoek der Materie (FOM), which is financially supported by the Nederlandse Organisatie voor Wetenschappelijk Onderzoek (NWO). This work was performed in the cooperation framework of Wetsus, Centre of Excellence for Sustainable Water Technology. Wetsus is co-funded by the Dutch Ministry of Economic Affairs and Ministry of Infrastructure and Environment, the European Union Regional Development Fund, the Province of Fryslân, and the Northern Netherlands Provinces.

\section{References}

1. Teng HH, Dove PM, De Yoreo JJ (2000) Kinetics of calcite growth: Surface processes and relationships to macroscopic rate laws. Geochim Cosmochim Acta 64: 2255-2266.

2. Spanos N, Koutsoukos PG (1998) Kinetics of precipitation of calcium carbonate in alkaline $\mathrm{pH}$ at constant supersaturation, Spontaneous and seeded growth. $J$ Phys Chem B 102: 6679-6684.

3. Busenberg E, Plummer LN (1989) Thermodynamics of Magnesian Calcite Solid-Solutions at 25-Degrees-C and 1-Atm Total Pressure. Geochim Cosmochim Acta 53: 1189-1208.

4. Christoffersen J, Christoffersen MR (1990) Kinetics of Spiral Growth of Calcite Crystals and Determination of the Absolute Rate-Constant. J Cryst Growth 100: 203-211.

5. Godinho JRA, Stack AG (2015) Growth Kinetics and Morphology of Barite Crystals Derived from Face-Specific Growth Rates. Cryst Growth Des 15 2064-2071.

6. Pina CM, Becker U, Risthaus P, Bosbach D, Putnis A (1998) Molecular-scale mechanisms of crystal growth in barite. Nature 395: 483-486.

7. Higgins SR, Bosbach D, Eggleston CM, Knauss KG (2000) Kink dynamics and step growth on barium sulfate (001): A hydrothermal scanning probe microscopy study. J Phys Chem B 104: 6978-6982. 
Citation: Liszka BM, Lenferink ATM, Otto C (2016) Growth Rate and Morphology of a Single Calcium Carbonate Crystal on Polysulfone Film Measured with Time Lapse Raman Micro Spectroscopy. J Anal Bioanal Tech 7: 321. doi:10.4172/2155-9872.1000321

Page 6 of 6

8. Bracco JN, Grantham MC, Stack AG (2012) Calcite Growth Rates As a Function of Aqueous Calcium-to-Carbonate Ratio, Saturation Index, and Inhibitor Concentration: Insight into the Mechanism of Reaction and Poisoning by Strontium. Cryst Growth Des 12: 3540-3548.

9. McEvoy AL, Stevens F, Langford SC, Dickinson JT (2006) Scanning-induced growth on single crystal calcite with an atomic force microscope. Langmuir 22 : 6931-6938.

10. Gratz AJ, Hillner PE, Hansma PK (1993) Step Dynamics and Spiral Growth on Calcite. Geochim Cosmochim Acta 57: 491-495.

11. Stipp SLS, Eggleston CM, Nielsen BS (1994) Calcite Surface-Structure Observed at Microtopographic and Molecular Scales with Atomic-Force Microscopy (Afm). Geochim Cosmochim Acta 58: 3023-3033.

12. Britt DW, Hlady V (1997) In-situ atomic force microscope imaging of calcite etch pit morphology changes in undersaturated and 1-hydroxyethylidene-1,1diphosphonic acid poisoned solutions. Langmuir 13: 1873-1876.

13. Teng HH, Dove PM, Orme CA, De Yoreo JJ (1998) Thermodynamics of calcite growth: baseline for understanding biomineral formation. Science 282: 724 727

14. Dobson PS, Bindley LA, Macpherson JV, Unwin PR (2005) Atomic force microscopy investigation of the mechanism of calcite microcrystal growth under Kitano conditions. Langmuir 21: 1255-1260.

15. Pouget EM, Bomans PH, Goos JA, Frederik PM, de With G, et al. (2009) The initial stages of template-controlled $\mathrm{CaCO} 3$ formation revealed by cryo-TEM. Science 323: 1455-1458

16. Tlili MM, Ben Amor M, Gabrielli C, Joiret S, Maurin G, et al. (2002) Characterization of $\mathrm{CaCO} 3$ hydrates by micro-Raman spectroscopy. J Raman Spectrosc 33: 10-16

17. Herman RG, Bogdan CE, Sommer AJ, Simpson DR (1987) Discrimination among Carbonate Minerals by Raman-Spectroscopy Using the Laser Microprobe. Appl Spectrosc 41: 437-440.

18. Urmos J, Sharma SK, Mackenzie FT (1991) Characterization of Some Biogenic Carbonates with Raman-Spectroscopy. Am Mineral 76: 641-646.

19. Behrens G, Kuhn LT, Ubic R, Heuer AH (1995) Raman-Spectra of Vateritic Calcium-Carbonate. Spectrosc Lett 28: 983-995.

20. Gabrielli C, Jaouhari R, Joiret S, Maurin G (2000) In situ Raman spectroscopy applied to electrochemical scaling. Determination of the structure of vaterite. $J$ Raman Spectrosc 31: 497-501.
21. Mullin JW (2001) Crystallization. Butterworth-Heinemann, Oxford, UK.

22. Lide DR (2006) Hanbook for crystallization and Physics. Taylor\& Francis Group.

23. Guggenheim EA, Turgeon JC (1955) Specific Interaction of Ions. T Faraday Soc 51: 747-761.

24. Scatchard G (1936) Concentrated solutions of strong electrolytes. Chem Rev 51: 747-761.

25. Brönsted JN (1992) Studies on solubility. IV. The principle of the specific interaction of ions. J Am Chem Soc 44: 877-898.

26. Pully VV, Lenferink A, Otto C (2010) Hybrid Rayleigh, Raman and two-photon excited fluorescence spectral confocal, microscopy of living cells. J Raman Spectrosc 41: 599-608.

27. van Manen HJ, Kraan YM, Roos D, Otto C (2005) Single-cell Raman and fluorescence microscopy reveal the association of lipid bodies with phagosomes in leukocytes. Proc Natl Acad Sci USA 102: 10159-10164.

28. Porto SPS, Giordmai J, Damen TC (1966) Depolarization of Raman Scattering in Calcite. Phys Rev 147: 608.

29. Haüy RJ (1832) Traite de Mineralogie. Paris.

30. Deng Z, Habraken GJM, Peeters M, Heise A, de With G, et al. (2011) Fluorescein functionalized random amino acid copolymers in the biomimetic synthesis of $\mathrm{CaCO}_{3}$. Soft Matter 7: 9685.

31. Nehrke G, Reichart GJ, Van Cappellen P, Meile C, Bijma J (2007) Dependence of calcite growth rate and Sr partitioning on solution stoichiometry: Non-Kosse crystal growth. Geochim Cosmochim Acta 71: 2240-2249.

32. Gebrehiwet TA, Redden GD, Fujita Y, Beig MS, Smith RW (2012) The Effect of the $\mathrm{CO} 32-$ to $\mathrm{Ca} 2+$ Ion activity ratio on calcite precipitation kinetics and $\mathrm{Sr} 2+$ partitioning. Geochem Trans 13: 1.

33. Stack AG, Grantham MC (2010) Growth Rate of Calcite Steps As a Function of Aqueous Calcium-to-Carbonate Ratio: Independent Attachment and Detachment of Calcium and Carbonate lons. Cryst Growth Des 10: 1409-1413.

34. Perdikouri C, Putnis CV, Kasioptas A, Putnis A (2009) An Atomic Force Microscopy Study of the Growth of a Calcite Surface as a Function of Calcium/ Total Carbonate Concentration Ratio in Solution at Constant Supersaturation. Cryst Growth Des 9: 4344-4350.

35. Bracco JN, Stack AG, Steefel $\mathrm{Cl}$ (2013) Upscaling calcite growth rates from the mesoscale to the macroscale. Environ Sci Technol 47: 7555-7562.
Citation: Liszka BM, Lenferink ATM, Otto C (2016) Growth Rate and Morphology of a Single Calcium Carbonate Crystal on Polysulfone Film Measured with Time Lapse Raman Micro Spectroscopy. J Anal Bioanal Tech 7 : 321. doi:10.4172/2155-9872.1000321

\section{OMICS International: Publication Benefits \& Features}

\section{Unique features:}

- Increased global visibility of articles through worldwide distribution and indexing

Showcasing recent research output in a timely and updated manner

Special issues on the current trends of scientific research

Special features:

$700+$ Open Access Journals

$50,000+$ editorial team

Rapid review proces

Quality and quick editorial, review and publication processing

Indexing at major indexing services

Sharing Option: Social Networking Enabled

Authors, Reviewers and Editors rewarded with online Scientific Credits

Befter discount for your subsequent articles

Submit your manuscript at: http://www.omicsonline.org/submission 